\title{
Studies in the Flavin Series. Part XVII. ${ }^{1}$
}

\author{
By S. Ghisla and P. Hemmerich,* Fachbereich Biologie, University of Konstanz, Germany \\ C. Jefcoate, Department of Biochemistry, Edinburgh University Medical School, Teviot Place, Edinburgh \\ EH8 9AG
}

\begin{abstract}
The distribution of products from the reductive alkylation of 1,3,7,8-tetramethylalloxazine depends upon whether saturated (hard) or unsaturated (soft) alkylating agents are used. The former yield 5-alkylated 5.10-dihydroalloxazines and, under more drastic conditions, 5,5-dialkylated derivatves, while the latter (benzyl and allyl bromide) yield 4a-monoalkylated and 4a,5-dialkylated derivatives. The 5-alkyldihydroalloxazines are readily oxidised to the 5-alkylalloxazinium salts, which either undergo hydrolytic dealkylation to the initial alloxazine or, if the 5-substituent is allyl or benzyl, in part rearrange to a 6-alkylalloxazine. Oxygen, under acidic conditions, converts 4a-benzyl- (or allyl)-dihydroalloxazines into the 6-benzyl- (or allyl-)alloxazine via the 5-substituted alloxazinium salt. The mechanisms of these reactions are discussed and their relevance to group transfer reactions of flavocoenzymes is stressed.
\end{abstract}

Previous papers have dealt with the alkylations of three classes of (iso)alloxazines: $†$ (i) 1,5-dihydroisoalloxazines (flavohydroquinones); ${ }^{1-4}$ (ii) 5 -acetyl-1,5-dihydroisoalloxazines; ${ }^{1,5,6}$ and (iii) 5-acetyl-1,5-dihydroalloxazines. ${ }^{1,6}$ In the present paper the alkylations of 5,10-dihydroalloxazines $[\mathrm{N}(5)$ unprotected] are described.

Previous results indicated that the alkylations of dihydro(iso)alloxazines $\dagger$ can be described well by competition between frontier orbital and charge control effects. ${ }^{1,7}$ The atoms $\mathrm{N}(1), \mathrm{N}(3), \mathrm{O}(2)$, and $\mathrm{O}(4)$ operate as charge controlled sites, $\mathrm{C}(4 \mathrm{a})$ and $\mathrm{N}(5)$ as frontier orbital controlled sites, while $N(10)$ is probably intermediate in character. Thus the orientation of alkylation is determined by the hardness ${ }^{1}$ of the alkylation agent and by the substituents at the dihydro(iso)alloxazine nucleus. The effect of acetylation at $\mathrm{N}(5)$ is particularly marked since the most reactive frontier orbital position is then eliminated. Recently, the remarkable mobility of alkyl groups at the dihydro(iso)alloxazine nucleus [at $\mathrm{N}(5), \mathrm{N}(10)$, and $\mathrm{C}(4 \mathrm{a})$ ] has become apparent. ${ }^{1-3}$ Thus $1,2-(5 \longrightarrow 4$ a) and $1,3-$ $(10 \rightarrow 4$ a) alkyl rearrangements have been observed together with photo-activated oxidation of active 4a-substituents by molecular oxygen. We now report further unusual rearrangements of alkylated alloxazines.

\section{RESULTS}

Alkylations. - The 5,10-dihydroalloxazine (2) was prepared in situ by reduction of 1,3-dimethyl-lumichrome (1) with alkaline sodium dithionite and alkylations were carried out anaerobically with dimethyl sulphate, diethyl sulphate, allyl bromide, and benzyl bromide.

The reactions with saturated alkylating agents yielded mixtures of 5-monoalkylated dihydroalloxazines (3) and 5,5-dialkylated dihydroalloxazines (4) and could be performed so that either class of products predominated. The reactions with unsaturated ('activated') alkylating agents $(\mathrm{R}=$ benzyl or allyl) yielded mixtures of 4 a-mono-

+ Dihydro(iso)alloxazine has been used throughout this paper where statements apply to both dihydroisoalloxazines and to dihydroalloxazines.

1 Part XVI, C. R. Jefcoate, S. Ghisla, and P. Hemmerich, J. Chem. Soc. (C), 1971, 1689.

2 W. H. Walker, P. Hemmerich, and V. Massey, Helv. Chim. Acta, 1967, 50, 2269. alkylated dihydroalloxazines (5) and 4a,5-dialkylated dihydroalloxazines (8) (see Scheme 1).

The structure of these compounds was ascertained as follows. The 5-monoalkylated compounds (3) are easily oxidised in acidic solution to yield alloxazinium salts $(6)$ $\left(\lambda_{\max }, 455\right.$ and $398 \mathrm{~nm}$ ). These are dealkylated upon raising the $\mathrm{pH}$ to 6 to yield dimethyl-lumichrome (1) quantitatively (see Figure 1). This dealkylation proceeds without the intermediate formation of a 4a-hydroxyadduct (pseudo-base), which has been observed in the isoalloxazine series. $^{3}$ The 5,5-dialkylated compounds (4) were isolated as the quaternary salts $\left(\lambda_{\max } 315\right.$ and $\left.285 \mathrm{~nm}\right)$ which yielded mesoionic compounds $(7)\left(\lambda_{\max } 345\right.$ and 305 $\mathrm{nm})$ upon neutralization [deprotonation at $\mathrm{N}(10)]$, with a $\mathrm{p} K$ of 6.6 (Figure 2). The salts as well as the mesoionic compounds were stable to oxygen. The 5,5-disubstituted compounds (4) were easily converted into the 5-monosubstituted alloxazinium salts (6) by oxidation with sodium nitrite in acid solution. Under more drastic conditions of oxidation $\left(6 \mathrm{~N}-\mathrm{HCl}-\mathrm{NaNO}_{2}, 90^{\circ}\right)$ the salts $(6)$ were converted into dimethyl-lumichrome (1). The n.m.r. spectra of the alkylated compound $(4 ; \mathrm{R}=\mathrm{Me})$ show one sharp signal corresponding to two equivalent methyl groups, which indicates double substitution at a cationic centre. In the case of the diethyl compound ( $4 ; \mathrm{R}=\mathrm{Et}$ ) the n.m.r. spectrum shows an ABX signal due to the nonequivalence of the ethylenic protons attached to a diastereoisotopic centre $\mathrm{N}(5)$. A more extensive discussion of this has been given for the analogous isoalloxazine compound. 4

The 4a-monosubstituted compounds $(5 ; \mathrm{R}=$ benzyl and allyl) were similiar to the 4a-substituted dihydroisoalloxazine analogues ${ }^{2,3}$ and were clearly identified from the n.m.r. and absorption spectra $\left(\lambda_{\max }, 360 \mathrm{~nm}\right)$. Both 4a-alkylated dihydroalloxazines $(5 ; \mathrm{R}=$ benzyl and allyl) were easily photolysed by light in the presence of oxygen to yield 1,3-dimethylalloxazine (1) quantitatively, while the 4a,5-dialkylated products $(8 ; \mathrm{R}=$ allyl and benzyl) were stable. The 4a-substituted dihydroalloxazines (5) were not further alkylated under the standard alkylation

${ }^{3}$ W. H. Walker, P. Hemmerich, and V. Massey, European J. Biochem., 1970, 13, 258.

4 P. Hemmerich, S. Ghisla, U. Hartmann, and F. Müller in 'Flavins and Flavoproteins,' ed. E. C. Slater, University Park Press, Baltimore, 1970.

5 P. Hemmerich, B. Prijs, and H. Erlenmeyer, Helv. Chim. Acta, 1960, 43, 372.

S. H. Dudley and P. Hemmerich, Helv. Chim. Acta, 1960, 50, 355.

7 G. Klopman, J. Amer. Chem. Soc., 1968, 90, 223. 
conditions and thus the 4a,5-dialkylated dihydroalloxazines (8), which were obtained from reductive benzylation and allylation of (1), were not formed by further alkylation of the 4a-alkylated product (5).
$100{ }^{\circ} \mathrm{C}$ a yellow precipitate slowly formed, the spectral properties of which suggested extensive rearrangement. The i.r. $[\nu(C O)]$ and absorption spectra $\left(\lambda_{\max }, 385\right.$ and 351 $\mathrm{mm})$ for $(5 ; \mathrm{R}=$ allyl) indicated a chromophore analogous<smiles>[R][N+]1([R])C(=C)C(C)=NC(C)=C1C</smiles><smiles>[R][N+]1([R])C(=C)C(=O)N(C)C2=C1NC(=C)C(=O)N2C</smiles><smiles>[C]1=CC=C1</smiles>

(4)<smiles>[R]N1C(=C)C(=C)N=C2N(C)C(=O)N(C)C(=O)C21[R]</smiles>

(8)<smiles>C=C1Nc2c(n(C)c(=O)n(C)c2=O)NC1=C</smiles>

(2)<smiles>Cc1ccc2c(C)ccc3nc4c(=O)n(C)c(=O)n4c3nc2c1</smiles>

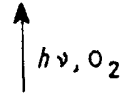

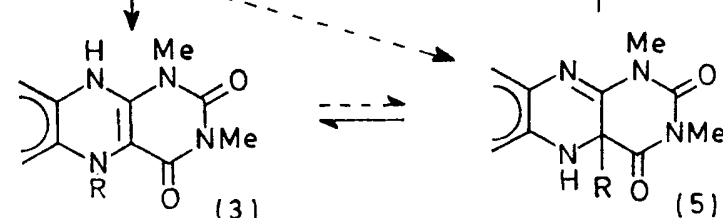

(3)<smiles></smiles>

(6)<smiles>[R]c1cccc2nc3c(nc12)c(=O)n(C)c(=O)n3C</smiles>

(1)

Schеме 1 Reagents: (i), $\mathrm{NaOH}-\mathrm{RX}$; (ii), $\mathrm{O}_{2}-6 \mathrm{~N}-\mathrm{HCl}$; (iii), heat

Alkyl Migration.-When the 4a-benzyldihydro- or 4a-allyldihydro-alloxazine $(5 ; \mathrm{R}=$ benzyl or allyl) was dissolved in an aqueous mineral acid-ethanol mixture at

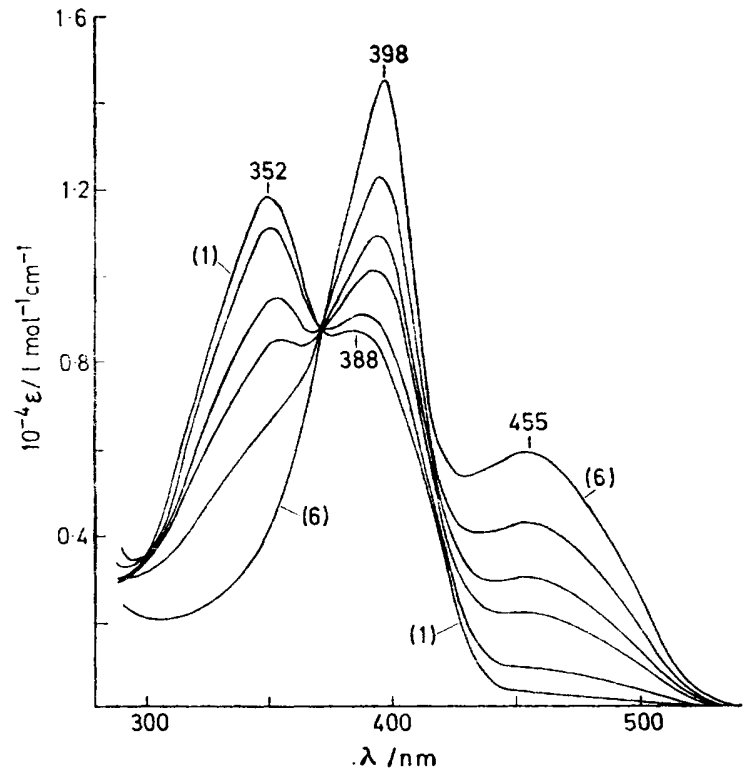

FIGURE 1 Direct hydrolysis of the alloxazinium salt $(6 ; \mathrm{R}=$ $\mathrm{Me})$ to 1,3-dimethyl-lumichrome (1) in aqueous solution at $24^{\circ}$ and $\mathrm{pH} 7$, half-time $6 \mathrm{~min}$. to that of alloxazine (1). The following experiments have indicated that these rearrangement products were 6-substituted alloxazines (9; $\mathrm{R}=$ benzyl or allyl).

The n.m.r. data shown in Table 1 (cf. refs. 8 and 9) suggest that the rearrangement product is a 6 -substituted

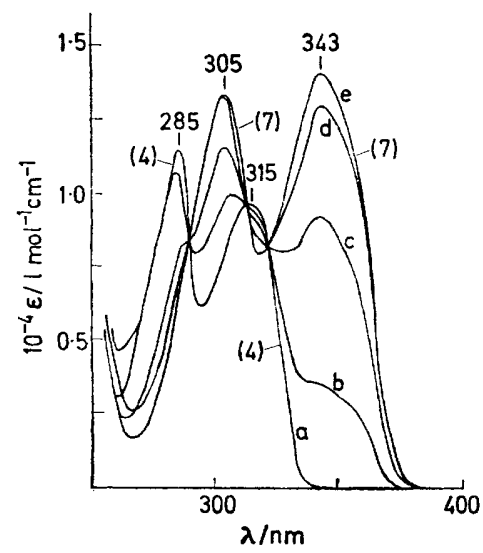

FIGURE 2 Absorption spectra of the conversion of the quaternary dihydroalloxazine salt (4) into the mesoionic form (7) in $0.1 \mathrm{M}$-aqueous buffers: (a) sodium sulphate $\mathrm{pH} 2 \cdot 0$; (b) potassium phosphate $\mathrm{pH} 6 \cdot 0$; (c) $\mathrm{pH} 7 \cdot 0$; (d) $\mathrm{pH} 7 \cdot 6$; and (e) sodium borate $\mathrm{pH} 9.0$

8 J. Lauterwein and P. Hemmerich, unpublished results.

F. J. Bullock and O. Jardetzky, J. Org. Chem., 1965, 30, 
alloxazine. Previous work with deuterium-labelled isoalloxazines has indicated that the chemical shift of the 7-Me protons is upfield from that of the 9-Me protons. The signals due to $6-\mathrm{H}, 9-\mathrm{H}, 7-\mathrm{Me}$, and $8-\mathrm{Me}$ were assigned by assuming that these signals retained the same relative shifts as in the isoalloxazine series. Comparison of the n.m.r. spectra of the allyl and benzyl rearrangement

\section{TABLE 1}

Characteristics of n.m.r. spectra of (iso)alloxazine derivatives

\begin{tabular}{|c|c|c|c|c|c|}
\hline & & & $\delta / p \cdot p$ & p.m. & \\
\hline Compound & Solvent & 7-Me & 8-Me & 9-H & $6-\mathrm{H}$ \\
\hline $\begin{array}{l}\text { 1,3-Dibenzyl-7,8-dimethyl- } \\
\text { alloxazine } a\end{array}$ & $\mathrm{CDCl}_{3}$ & $\begin{array}{c}c a . \\
2 \cdot 50\end{array}$ & $\begin{array}{c}c a . \\
2 \cdot 50\end{array}$ & $7 \cdot 78$ & $8 \cdot 00$ \\
\hline $\begin{array}{l}\text { alloxazine (9) } \\
\text { 6-Benzyl-1 } 378 \text {-tetra- }\end{array}$ & $\mathrm{CDCl}_{3}$ & $2 \cdot 48$ & $2 \cdot 58$ & $7 \cdot 75$ & \\
\hline $\begin{array}{l}\text { 6-Benzyl-1,3,7,8-tetra- } \\
\text { methylalloxazine }(9) \\
\text { 9-Deuterio-7 8-dimethyl- }\end{array}$ & $\begin{array}{l}\mathrm{CDCl}_{3} \\
0 \cdot 2 \mathrm{M}-\end{array}$ & $2 \cdot 43$ & 2.52 & $7 \cdot 76$ & \\
\hline $\begin{array}{l}\text { 9-Deuterio-7,8-dimetnyl- } \\
\text { isoalloxazine } 9\end{array}$ & $\mathrm{NaOD}$ & $2 \cdot 23$ & $2 \cdot 30$ & $(6 \cdot 89)^{b}$ & $7 \cdot 08$ \\
\hline $\begin{array}{l}\text { 8-Trideuterioflavin mono- } \\
\text { nucleotide }\end{array}$ & $\mathrm{D}_{2} \mathrm{O}^{c}$ & $2 \cdot 30$ & $(2 \cdot 47)^{b}$ & b $7 \cdot 39$ & 7.68 \\
\hline
\end{tabular}

products with the spectrum of 1,3-dibenzyl-7,8-dimethylalloxazine suggests the probable loss of the 6-proton resonance for both rearrangement products, implying that the 6 -proton has been replaced by allyl or benzyl substituents. Furthermore the 8-Me group appeared as a doublet $(J 2 \mathrm{~Hz})$ due to 1,3 -coupling with $9-\mathrm{H}^{,{ }^{10}}$ while the 7-Me group showed a sharp singlet, which is consistent with the substitution at $\mathrm{C}(6)$. Clearly the small separations of the 6- and 9-proton resonances and the 7- and 8-Me resonances make these assignments uncertain.

However, confirmatory evidence that the benzyl or allyl group had migrated to the 6- not to the 9-position, was provided by the observation that alloxazine (9) did<smiles>[R]c1cccc2nc3c(c(=O)n(C)c(=O)n3C)n1[C@H]1CCCCCC1(C)CCCC2</smiles>

SCHEME 2

not complex with $\mathrm{Cu}^{2+}$ ions (Figure 3 ), even in the presence of a 10-fold excess of $\mathrm{Cu}^{2+}$ ions. In the control experiment, the alloxazine (1) (6-position unsubstituted) and its 9-bromo-derivative both showed a new absorption band $\left(\lambda_{\max } 410 \mathrm{~nm}\right)$ due to unhindered complexing of $\mathrm{Cu}^{2+}$ at the 4-and 5-position (Scheme 2). ${ }^{8,11}$ The analogous 6-allylalloxazine $(9 ; \mathrm{R}=$ allyl), which was isolated by oxidation of the dihydroalloxazine $(5 ; \mathrm{R}=$ allyl) with oxygen in acid solution, also failed to complex with $\mathrm{Cu}^{2+}$ ions.

The same alloxazine $(9 ; \mathrm{R}=$ benzyl) has been synthesised by an alternative procedure which gives more insight into the mechanism of the rearrangement. When

10 M. Barfield and B. Chakrabarti, Chem. Rev., 1969, 69, 757.

11 F. Müller, P. Hemmerich, and A. Ehrenberg, European $j$. Biochem., 1968, 5, 158; P. Bamberg and P. Hemmerich, Helv. Chim. Acta, 1961, 44, 1001. the 4a-benzyldihydroalloxazine $(5 ; R=$ benzyl $)$ was treated in acetic acid with a platinum-silica catalyst under hydrogen, the absorption spectrum of the product

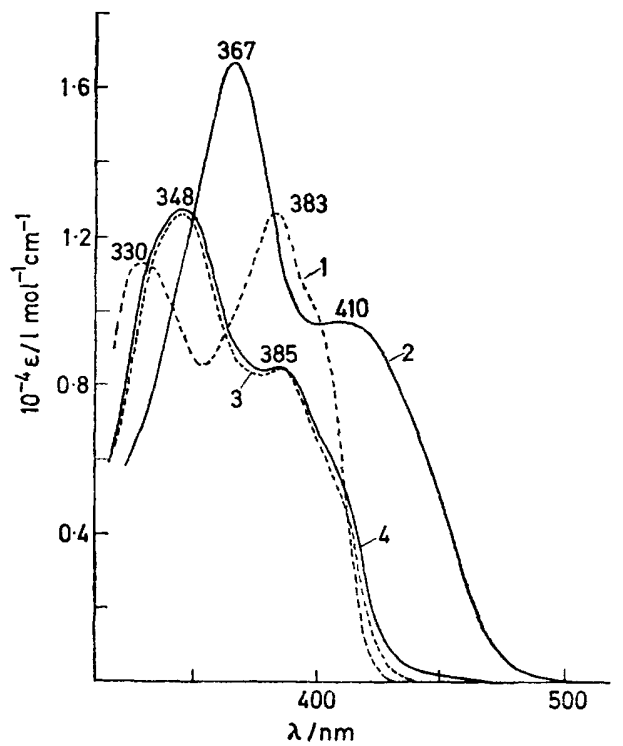

FIGURE 3 Effect of substitution at position 6 on complex formation by alloxazines with $\mathrm{Cu}^{2+}$ in acetone. Spectrum I and spectrum 3: the absorption spectra of 1,3-dimethyllumichrome (1) and 6-benzyl-1,3,7,8-tetramethylalloxazine (9) in absence of $\mathrm{Cu}^{2+}$. Spectrum 2: The spectrum of 1,3-dimethyl-lumichrome (1) after addition of $2 \cdot 0 \mathrm{~mol}$. equiv. $\mathrm{Cu}\left(\mathrm{ClO}_{4}\right)_{2}$. Spectrum 4: The spectrum of the alloxazine (9) after addition of $2 \cdot 0$ mol. equiv. $\mathrm{Cu}\left(\mathrm{ClO}_{4}\right)_{2}$.

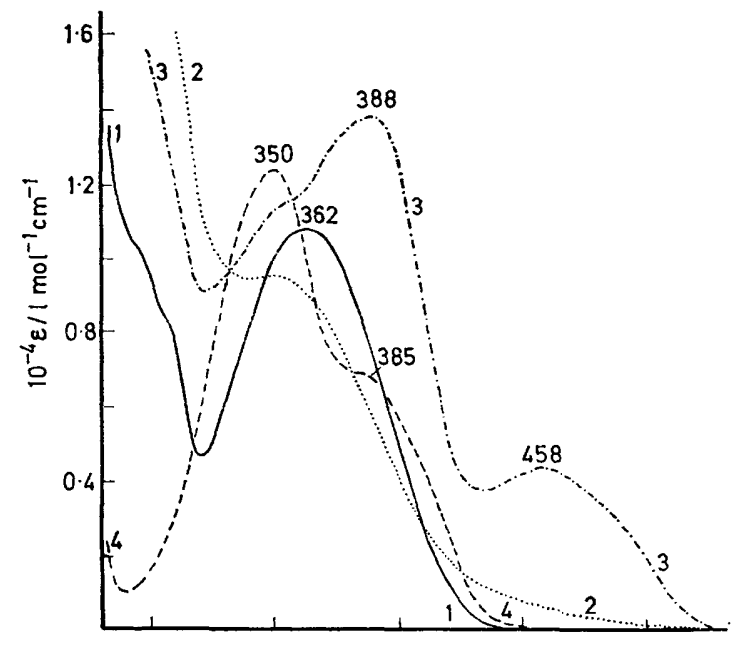

$\lambda / \mathrm{nm}$

FIGURE 4 Isomerisation of 4 a-benzyldihydroalloxazine (5) to 6 -benzylalloxazine $(9)$ followed by means of absorption spectra. Absorption spectrum of (5) in acetic acid (spectrum 1) and after reduction by $\mathrm{H}_{2}-\mathrm{Pt}$ (spectrum 2). The spectrum is typical of 5 -substituted dihydroalloxazines; 12 probably a mixture of 5-benzyl-5,10-dihydroalloxazine (3) and 5,10-dihydroalloxazine (2). Spectrum 3: immediately after admission of oxygen showing instantaneous formation of a 5-substituted alloxazinium salt (6) (cf. Figure 1). Spectrum 4: 6-benzylalloxazine (9) after separation from lumichrome (1). The total reaction sequence is $(5) \longrightarrow\{(2)+(3)\} \stackrel{\mathrm{O}_{2}}{\longrightarrow}$ $\{(1)+(6)\} \longrightarrow\{(1)+(9)\}$ 
changed towards that of the 5,10-dihydroalloxazine structure (4; $R=$ benzyl) (Figure 4). ${ }^{12}$ Admission of oxygen immediately produced a new absorption at $458 \mathrm{~nm}$, which then decreased over the next $30 \mathrm{~min}$. These spectral changes suggest that the 5-benzylalloxazinium salt (6; $\mathrm{R}=$ benzyl) is an intermediate [for comparison Figure 1 shows the spectrum of $(6 ; \mathrm{R}=\mathrm{Me})]$. T.l.c. showed two spots correspondingly to the 1,3 ,dimethylalloxazine (1) and the 6-benzyl-1,3-dimethylalloxazine $(9 ; \mathrm{R}=$ benzyl), both of which were isolated and identified.

\section{DISCUSSION}

The alkylations in the dihydroalloxazine series (see Table 2) are largely analogous to the corresponding reactions in the dihydroisoalloxazine series. ${ }^{4-6}$ It was previously suggested ${ }^{1}$ that this distinction between exclude the possibility that the 4a,5-dialkyldihydroalloxazines $(8 ; \mathrm{R}=$ benzyl or allyl) were formed by a direct alkylation at $\mathrm{C}(4 \mathrm{a})$ of the 5 -monoalkylated intermediates $(3 ; \mathrm{R}=$ benzyl or allyl).

The proportion of the $4 \mathrm{a}$-alkylated dihydroalloxazine ( 5 ; $\mathrm{R}=$ benzyl or allyl) which is formed respectively by direct alkylation at $\mathrm{C}(4 \mathrm{a})$ and by a rearrangement of an initial $\mathrm{N}(5)$ isomer, has not been determined. The 5-alkylated dihydroalloxazines $(3 ; \mathrm{R}=$ benzyl or allyl) have not been detected, even though the dihydroisoalloxazine analogues have been isolated. However even the latter readily undergo $5 \rightarrow 4$ a migration at $50{ }^{\circ} \mathrm{C}^{2}$ On the other hand saturated alkyl substituents do not show this $5 \longrightarrow 4$ a migration in the dihydroalloxazine series, while migration occurs under more drastic conditions in the iso-series. ${ }^{1}$

TABLE 2

Reductive monoalkylation of (iso)alloxazines

\begin{tabular}{|c|c|}
\hline $\begin{array}{l}\text { Prealkylated } \\
\text { positions }\end{array}$ & $\begin{array}{c}\text { Protective } \\
\text { group at } \\
\text { (N5) } \\
\text { None }\end{array}$ \\
\hline $\begin{array}{l}\text { Isoalloxazine } \\
\text { (Flavin) }\end{array}$ & $\begin{array}{l}\text { None } \\
\text { Acetyl } \\
\text { Acetyl }\end{array}$ \\
\hline $\begin{array}{l}\text { Alloxazine } \\
\text { (Lumichrome) }\end{array}$ & $\begin{array}{l}\text { None } \\
\text { None } \\
\text { Acetyl } \\
\text { Acetyl }\end{array}$ \\
\hline
\end{tabular}

hard (aikvl) and soft (benzyl, allyl) alkylating agents was due to an increase in hardness of $N(5)$ compared to $C(4 a)$, which was caused by the bending of the molecule about the $\mathrm{N}(5)-\mathrm{N}(10)$ axis. However, the benzylation and allylation of the dihydroalloxazine (2) were complicated by the ease of alkyl migration between $\mathrm{N}(5)$ and $\mathrm{C}(4 \mathrm{a})$. The 5-benzyldihydroalloxazine (3; $\mathrm{R}=$ benzyl) was established as an intermediate in benzylation of (2) by the isolation of the 4a,5-dibenzyldihydroalloxazine $(8 ; \mathrm{R}=$ benzyl) from the reaction. Since the 4a-benzyldihydroalloxazine (5; $\mathrm{R}=$ benzyl) could not be further benzylated to this product, the 4a,5-dibenzyl compound ( 8 ; $\mathrm{R}=$ benzyl) must have been formed by alkylation of the 5-benzyl intermediate (3; R = benzyl), either directly or more probably by rearrangement of an intermediate dibenzyl quarternary salt $(4 ; \mathrm{R}=$ benzyl). The dialkyl quarternary salt (4; $\mathrm{R}=\mathrm{Et}$ or $\mathrm{Me}$ ), which was isolated from reductive alkylation of $(1)$, rearranged at $150^{\circ}$ to the $4 \mathrm{a}, 5$-dialkyldihydroalloxazine $(8 ; \mathrm{R}=\mathrm{Et}$ or $\mathrm{Me})$. Since these alkyl substituents have a far lower migratory aptitude than benzyl or allyl substituents, we may conclude that the dibenzyl or diallyl quarternary salts $(4 ; \mathrm{R}=$ benzyl allyl) will rearrange rapidly, even at the lower temperatures of the alkylation $\left(20^{\circ} \mathrm{C}\right)$. However, we cannot

12 K. H. Dudley, A. Ehrenberg, P. Hemmerich, and F. Müller, Helv. Chim. Acta, 1964, 17, 1354.

\begin{tabular}{|c|c|c|c|c|}
\hline \multicolumn{4}{|c|}{ Alkylated product yield $(\%)$} & \multirow[b]{2}{*}{ Ref. } \\
\hline $\mathbf{N}(5)$ & $\mathrm{N}(10)$ & $\mathrm{C}(\mathbf{4 a})$ & $\mathrm{O}(2)$ & \\
\hline \multirow[t]{2}{*}{$80-100 *$} & & $\begin{array}{c}0 \longrightarrow 20^{a} \\
>95\end{array}$ & & \\
\hline & & & $\begin{array}{l}>95 \\
>95\end{array}$ & $\begin{array}{l}1,5,6 \\
1,5,6\end{array}$ \\
\hline \multirow[t]{3}{*}{$>95$} & & & & \\
\hline & 95 & 5 & & 1,6 \\
\hline & $\begin{array}{l}30 \\
70\end{array}$ & $\begin{array}{l}70 \\
30\end{array}$ & & \\
\hline
\end{tabular}

The 5,5-dialkyldihydroalloxazine salts (4) were readily characterised by the $\mathrm{pH}$ sensitivity of the absorption spectra (Figure 2). The spectral changes indicated a $\mathrm{pK}$ of $\mathbf{6 \cdot 6}$ for loss of $10-\mathrm{H}$ and formation of a zwitter-ion. The unusually high acidity of the 10-proton can in part be attributed to the electron-withdrawing effect of the quarternary nitrogen group.

The alloxazinium salts $(6 ; \mathrm{R}=$ allyl or benzyl) appear to be formed by acid oxidation of $4 \alpha$-alkyldihydroalloxazines $(5 ; \mathrm{R}=$ allyl or benzyl), but are only intermediates, since they either further rearrange to the 6 -alkylalloxazine $(9 ; \mathrm{R}=$ allyl or benzyl) or undergo hydrolysis to alloxazine (1). The $4 \mathrm{a} \rightarrow 5$ rearrangement requires an initial oxidation step, since acid, in the absence of oxygen, did not isomerize (5) into (4). The most likely sequence for the rearrangement is that (5) is first oxidised to an unstable 4a-substituted alloxazine radical, which then rearranges to a more stable 5-substituted alloxazine radical. ${ }^{13} \mathrm{~A}$ further oxidation of the 5-substituted radical then produces the alloxazinium salt (6).

In contrast to the ' $i$ so'-series, ${ }^{3}$ a stable 'pseudobase ' is not formed upon neutralization of the alloxazinium salt (6), and instead immediate dealkylation occurs yielding 1,3-dimethyl-lumichrome (1) (cf. Figure 1).

13 F. Müller, P. Hemmerich, A. Ehrenberg, G. Palmer, and V. Massey, European J. Biochem., 1970, 14, 185. 
This is similar to a known reaction in the phenazine series. ${ }^{14}$ Thus, alloxazinium salts (6) can function as strong alkyl donors to appropriate nucleophiles. This behaviour may provide a model for flavin-dependent biological dehydrogenations, as well as hydrofolatedependent monocarbon-transfer., $4,15,16$

\section{EXPERIMENTAL}

M.p.s were determined with a Kofler hot-stage apparatus and are corrected. Thin layer chromatography (t.l.c.) was carried out on MN-Silicagel S (Macherey, Nagel Co., Düren, Germany) with chloroform-ethanol $(7: 3, \mathrm{v} / \mathrm{v})$, Absorption spectra were measured with a Cary 14 spectrophotometer. I.r. spectra were taken on a Beckman IR 8 or on a Perkin-Elmer 621 and ${ }^{1} \mathrm{H}$ n.m.r. spectra on a Varian A-60 A instrument.

General Procedures for Reductive Alkylation of 1,3-Dimethyl-lumichrome (1).-A stirred suspension of 1,3-dimethyl-lumichrome (1) $(1.0 \mathrm{~g})$ in a mixture of ethanol $(50 \mathrm{ml})$ and aqueous $2 \mathrm{~N}$-sodium hydroxide $(40 \mathrm{ml})$ was reduced anaerobically with a small excess of solid sodium dithionite. The alkylating agent (10 equiv. in $10 \mathrm{ml}$ ethanol) was added to the reddish yellow solution over $30 \mathrm{~min}$. The reaction was followed by t.l.c. and at completion the products were isolated as described below.

(a) Methylation with dimethyl sulphate. During the reaction a yellow precipitate of the sodium salt of 5,10-dihydro-1,3,5,7,8-pentamethylalloxazine $(3 ; \quad \mathrm{R}=\mathrm{Me})$ gradually formed, which dissolved completely on acidification with acetic acid. After evaporation of the ethanol in vacuo, $2 \mathrm{~N}$-perchloric acid $(50 \mathrm{ml})$ and solid sodium perchlorate $(2 \mathrm{~g})$ were added and the mixture was oxidised with solid sodium nitrite $(500 \mathrm{mg})$. An orange product was formed, filtered off, and subsequently washed with water, methanol, chloroform, and ether, and dried in vacuo, to give 1,3,5,7,8-pentamethylalloxazinium perchlovate $(6 ; \mathrm{R}=\mathrm{Me})(0.75 \mathrm{~g})$, m.p. $238-242^{\circ}$ (Found: C, 46.7; $\mathrm{H}, 4.4 ; \mathrm{N}, 14 \cdot 5$. $\mathrm{C}_{15} \mathrm{H}_{17} \mathrm{ClN}_{4} \mathrm{O}_{6}$ requires $\mathrm{C}, 46 \cdot 8 ; \mathrm{H}$, $4.45 ; \mathrm{N}, 14.55 \%), \lambda_{\max }(6 \mathrm{~N}-\mathrm{HCl}) 455$ and $398 \mathrm{~nm}(\log \varepsilon$ 3.81 and $4 \cdot 19), \lambda_{\max }(\mathrm{KBr}) 1725(4-\mathrm{C}=\mathrm{O})$ and $1095 \mathrm{~cm}^{-1}$ $\left(\mathrm{ClO}_{4}^{-}\right), \delta\left(\mathrm{CF}_{3} \mathrm{CO}_{2} \mathrm{H}\right) \quad 8 \cdot 19$ and $8 \cdot 3(6-$ and $9-\mathrm{H}), \quad 5 \cdot 27$ (5-Me), and 2.71 and 2.77 p.p.m. (7- and 8-Me).

The combined washings were concentrated in vacuo to yield 5,10-dihydro-1,3,5,5,7,8-hexamethylalloxazinium perchlorate $(4 ; \mathrm{R}=\mathrm{Me})(0 \cdot 27 \mathrm{~g})$, m.p. $268-270^{\circ}$ (from methanol-acetone) (Found: C, 47.95; H, 5.2; N, 13.9. $\mathrm{C}_{16} \mathrm{H}_{21}$ $\mathrm{ClN}_{4} \mathrm{O}_{6}$ requires $\left.\mathrm{C}, 47.95 ; \mathrm{H}, 5.3 ; \mathrm{N}, 14.0 \%\right), \lambda_{\max }(6 \mathrm{~N}-$ $\mathrm{HCl}) 315$ and $287 \mathrm{~nm}\left(\left(\log \varepsilon 3.97\right.\right.$ and 4.07), $\lambda_{\max .}(\mathrm{pH} 9)$ 343 and $305 \mathrm{~nm}(\log \varepsilon 4 \cdot 13$ and $4 \cdot 12)$.

(b) Ethylation with diethyl sulphate. No formation of a precipitate was observed. The mixture was acidified with acetic acid, the ethanol was distilled off under reduced pressure, and the aqueous residue was extracted five times with chloroform. The organic layer was washed twice with $2 \mathrm{~N}$-ammonia containing dithionite, with diluted mineral acid, and with a saturated sodium hydrogen carbonate solution, dried $\left(\mathrm{MgSO}_{4}\right)$, and the solvent was distilled off under reduced pressure. The oily residue deposited a white precipitate on treating with chloroform-

\footnotetext{
14 'Heterocyclic Compounds,' ed. R. C. Elderfield, vol. 6 , Wiley, New York, 1956, p. 654.

15 P. Hemmerich, G. Nagelschneider, and C. Veeger, FEBS Letters, 1970, 8, 69 .
}

isopropyl ether. This product was dissolved in methanol $(10 \mathrm{ml})$, a solution of sodium perchlorate $(0.5 \mathrm{~g})$ in $2 \mathrm{~N}-$ perchloric acid $(5 \mathrm{ml})$ was added, and the methanol was slowly distilled off in vacuo until a solid was formed. The crystals were filtered and recrystallized from ethanol$2 \mathrm{~N}$-perchloric acid to give 5,5-diethyl-5,10-dihydro-1,3,7,8tetramethylalloxazinium perchlorate $(4 ; \mathrm{R}=\mathrm{Et})(0 \cdot 6 \mathrm{~g})$, m.p. 235-238 ${ }^{\circ}, \mathrm{p} K_{\mathrm{a}} 6.6$ (Found: C, 50.3; H, 5.85; N, 13.0. $\mathrm{C}_{20} \mathrm{H}_{25} \mathrm{ClN}_{4} \mathrm{O}_{6}$ requires $\mathrm{C}, 50 \cdot 4 ; \mathrm{H}, 5 \cdot 9 ; \mathrm{N}, 13 \cdot 05 \%$ ), $\lambda_{\max }(6 \mathrm{~N}-\mathrm{HCl}) 315$ and $287 \mathrm{~nm}(\log \varepsilon 3.97$ and 4.07$) ; \lambda_{\max }$. (pH 9) 343 and $305 \mathrm{~nm}(\log \varepsilon 4 \cdot 14$ and $4 \cdot 12)$.

(c) Benzylation with benzyl bromide. The general procedure was repeated in tetrahydrofuran instead of ethanol (two-phase system). The pale yellow mixture was acidified with acetic acid, the tetrahydrofuran was distilled off under reduced pressure, and the residue was extracted thoroughly ${ }^{6}$ with chloroform. The organic layer was washed twice with a solution of sodium dithionite in aqueous [ $\mathrm{N}$-potassium hydroxide, then with diluted acetic acid, hydrogen carbonate, and water, and was finally dried $\left(\mathrm{MgSO}_{4}\right)$. The solvent was evaporated in vacuo and the oily residue crytallised from chloroform-isopropyl ether. A first fracton $(690 \mathrm{mg})$ of pure $4 \mathrm{a}$-benzyl-4a,5-dihydro-1,3,7,8-tetramethylalloxazine (5; R = benzyl) (m.p. $241-245^{\circ}$ ) was separated by filtration. This compound was identical with an authentic specimen. ${ }^{1}$

The mother liquor was evaporated in vacuo and the oily residue was crystallised twice from methanol to yield 4a,5-dibenzyl-4a,5-dihydro-1,3, 7,8-tetramethylalloxazine

(8; $\mathrm{R}=$ benzyl) $(520 \mathrm{mg})$, m.p. $167-168^{\circ}$ (from ethanol) (Found: $\mathrm{C}, 73 \cdot 7 ; \mathrm{H}, 6 \cdot 15 ; \mathrm{N}, 12 \cdot 35 . \mathrm{C}_{28} \mathrm{H}_{28} \mathrm{~N}_{4} \mathrm{O}_{2}$ requires C, 73.4; $\mathrm{H}, 6.25 ; \mathrm{N}, 12.4 \%$ ), $\lambda_{\max }(\mathrm{MeOH}), 340$ and $305 \mathrm{~nm}$ $(\log \varepsilon 3.68$ and 3.85$), \lambda_{\max }(6 \mathrm{~N}-\mathrm{HCl}) 355$ and $312 \mathrm{~nm}(\log \varepsilon$ $3 \cdot 60$ and $3 \cdot 95), \delta\left(\mathrm{CDCl}_{3}\right) 4 \cdot 45\left(5-\mathrm{PhCH}_{2}\right)$ and $3 \cdot 00$ p.p.m. (4a-PhCH $\mathrm{H}_{2}$ ).

(d) Allylation with allyl bromide. The crude product was recrystallised from methanol to give pure 4a-allyl4a,5-dihydro-1,3,7,8-tetramethylalloxazine $(5 ; \quad \mathrm{R}=$ allyl $)$ (300 mg), m.p. 143-146 and 210-230 (decomp.). This compound was identical to an authentic sample. ${ }^{1}$

6-Allyl-1,3,7,8-tetramethylalloxazine $\quad(7 ; \quad \mathrm{R}=$ allyl $) .-\mathrm{A}$ mixture of 5-acetyl-4a-allyl-4a,5-dihydro-1,3,7,8-tetramethylalloxazine and 5-acetyl-10-allyl-5,10-dihydro-1,3,7,8tetramethylalloxazine ${ }^{1}(250 \mathrm{mg})$ were dissolved in ethanolic $6 \mathrm{~N}$-hydrochloric acid $(1: 1)$ under a very slow stream of nitrogen at $80^{\circ}$. After $48 \mathrm{~h}$, the starting material had disappeared and formation of a new yellow fluorescent spot on t.l.c. was observed in addition to 1,3-dimethyllumichrome (1). The solution was diluted with the same volume of water and left at $0^{\circ}$ until completion of crystallisation. Filtration yielded yellow needles of 6-allyl-1,3,7,8tetramethylalloxazine $(9 ; \mathrm{R}=$ allyl $)(20 \mathrm{mg})$, m.p. $223-$ $226^{\circ}$ (Found: C, 65.3; H, 5.85; N, 17.65. $\mathrm{C}_{17} \mathrm{H}_{18} \mathrm{~N}_{4} \mathrm{O}_{2}$ requires $\mathrm{C}, 65 \cdot 8 ; \mathrm{H}, 5 \cdot 85 ; \mathrm{N}, \mathbf{1 8 . 0 5 \%}), \lambda_{\max }(\mathrm{MeOH})$ $388 \mathrm{~s}, 352,255$, and $222 \mathrm{~nm}(\log \varepsilon 3 \cdot 86,4 \cdot 10,4 \cdot 67$, and $4 \cdot 58)$, $\lambda_{\max }(6 \mathrm{~N}-\mathrm{HCl}) 395$ and $370 \mathrm{~nm}(\log \varepsilon 4.08$ and 4.07$) \nu_{\max }$ $\left(\mathrm{CHCl}_{3}\right) 1718(4-\mathrm{C}=\mathrm{O})$ and $1675 \quad(2-\mathrm{C}=\mathrm{O})$, no $v(\mathrm{~N}-\mathrm{H})$, $\delta\left(\mathrm{CDCl}_{3}\right) 7 \cdot 75(9-\mathrm{H}), 6 \cdot 4-4 \cdot 1(5 \mathrm{H}, \mathrm{m}$, allyl residue), and 2.58 p.p.m. (d, $J 1 \mathrm{~Hz}, 8-\mathrm{Me}$ ). The mother liquor contained only 1,3-dimethyl-lumichrome (1).

6-Benzyl-1,3,7,8-tetramethylalloxazine $(9 ; \mathrm{R}=$ benzyl).-

$16 \mathrm{~J}$. Stravinianopaulos and L. Kaenicke, European J. Biochem., 1967, 3, 95; M. C. Archer and K. G. Scrimgeour, Canad. J. Biochem., 1970, 48, 278. 
The same procedure as for $(9 ; \mathrm{R}=$ allyl) was performed with a mixture of 5-acetyl-4a-benzyl-4 $\alpha, 5$-dihydro-1,3,7,8tetramethylalloxazine and 5-acetyl-10-benzyl-5,10-dihydro1,3,7,8-tetramethylalloxazine ${ }^{1}(200 \mathrm{mg})$ to yield pure 6-benzyl-1,3,7,8-tetramethylalloxazine $(9 ; \mathrm{R}=$ benzyl $)(80$ $\mathrm{mg}$ ), m.p. $271-275^{\circ}$ (Found: C, 69.4; H, 5.7; N, 15.2. $\mathrm{C}_{21} \mathrm{H}_{20} \mathrm{~N}_{4} \mathrm{O}_{2}$ requires $\left.\mathrm{C}, 70 \cdot 0 ; \mathrm{H}, 5 \cdot 6 ; \mathrm{N}, 15 \cdot 55 \%\right), \lambda_{\max }$ $(\mathrm{MeOH}) 385 \mathrm{~s}$ and $351 \mathrm{~nm}(\log \varepsilon 3.86$ and $4 \cdot 11), \lambda_{\max }(6 \mathrm{~N}-$ $\mathrm{HCl}) 395$ and 370 ( $\log \varepsilon 4.08$ and $4 \cdot 07$ ), $\delta\left(\mathrm{CF}_{3} \mathrm{CO}_{2} \mathrm{H}\right) 8 \cdot 19$ $(9-\mathrm{H}), 4.92\left(6-\mathrm{PhCH}_{2}\right), 2.78(8-\mathrm{Me})$, and 2.52 p.p.m. (7-Me). 6-Benzyl-1,3,7,8-tetramethylalloxazine $(9 ; \quad \mathrm{R}=$ benzyl $)$ (Alternative Procedure).-4a-Benzyl-4a,5-dihydro-1,3,7,8tetramethylalloxazine (5; R= benzyl) $(400 \mathrm{mg})$ was dissolved in acetic acid $(50 \mathrm{ml})$ and hydrogenated over platinum on silica gel. T.l.c. showed two spots corresponding to 1,3-dimethyl-lumichrome (1) (blue fluoresence) and 6-benzyl-1,3,7,8-tetramethylalloxazine $(9 ; \mathrm{R}=$ benzyl) (yellow fluorescence). The latter was separated by careful fractional crystallisation from aqueous acetic acid and from chloroform-isopropyl ether to yield the pure alloxazine (9; $\mathrm{R}=$ benzyl) (75 mg), m.p. $270-275^{\circ}$.

5,10-Dihydro-1,3,5,5,7,8-hexamethylalloxazine $(7 ; \quad \mathrm{R}=$ $\mathrm{Me})$.- The perchlorate $(4 ; \mathrm{R}=\mathrm{Me})(1.0 \mathrm{~g})$ was dissolved in chloroform $(50 \mathrm{ml})$ and this solution washed twice with a saturated solution of sodium hydrogen carbonate, then with water, was dried $\left(\mathrm{MgSO}_{4}\right)$, and the solvent was distilled off under reduced pressure. The oily residue was treated with tetrahydrofuran-isopropyl ether and the crude product was collected by filtration (m.p. 186-190 $)$.
This compound was recrystallised from chloroformisopropyl ether to yield 5,10-dihydro-1,3,5,5,7,8-hexamethylalloxazine $(7 ; \mathrm{R}=\mathrm{Me})(0.68 \mathrm{~g})$, m.p. $191-193^{\circ}$ (Found: $\mathrm{C}, 63.8 ; \mathrm{H}, 6.75 ; \mathrm{N}, 18.4 . \mathrm{C}_{16} \mathrm{H}_{20} \mathrm{~N}_{4} \mathrm{O}_{2}$ requires $\mathrm{C}, 64.0 ; \mathrm{H}, 6.7 ; \mathrm{H}, 18.65 \%), \lambda_{\max }(\mathrm{MeOH}) 343$ and 305 $\mathrm{nm}(\log \varepsilon 4 \cdot 13$ and $4 \cdot 12)$. The corresponding 5,5-diethyl5,10-dihydro-1,3,7,8-tetramethylalloxazine $\quad(7 ; \quad \mathrm{R}=\mathrm{Et})$ (m.p. $144-145^{\circ}$ ), which was prepared in the same way, has the same spectral characteristics as the dimethyl compound ( $7 ; \mathrm{R}=\mathrm{Me}$ ).

4a,5-Dihydro-1,3,4a,5,7,8-hexamethylalloxazine $(8 ; \mathrm{R}=$ $\mathrm{Me})$.- The alloxazine $(4 ; \mathrm{R}=\mathrm{Me})(0.5 \mathrm{~g})$ in a small glass tube was heated at $190-195^{\circ}$ for $30 \mathrm{~s}$. The resulting yellow brown oil showed a single, yellow fluorescent spot on t.l.c. It was dissolved in methanol $(2 \mathrm{ml})$, the solution was treated with charcoal, and water was added until the beginning of turbidity. Yellow-brown crystals separated after standing at $10^{\circ}$ overnight and were recrystallised from methanol-water to yield $4 \mathrm{a}, 5$-dihydro-1,3,4a,5,7,8hexamethylalloxazine $(8 ; \mathrm{R}=\mathrm{Me})(0.41 \mathrm{~g}), \mathrm{m} . \mathrm{p} .131-$ $133^{\circ}$ (Found: $\mathrm{C}, 64 \cdot 1 ; \mathrm{H}, 6 \cdot 7 ; \mathrm{N}, 18 \cdot 6 . \mathrm{C}_{16} \mathrm{H}_{20} \mathrm{~N}_{4} \mathrm{O}_{2}$ requires $\mathrm{C}, 64 \cdot 0 ; \mathrm{H}, 6 \cdot 7 ; \mathbf{1 8 \cdot 6 5 \%}), \lambda_{\max }(\mathrm{EtOH}) 375 \mathrm{~s}, 300$, 260 , and $215 \mathrm{~nm}(\log \varepsilon 3 \cdot 310,3 \cdot 890,4 \cdot 190$, and $4 \cdot 412)$, $\lambda_{\max }(\mathrm{pH} 7) 303$ and $220 \mathrm{~nm}(\log \varepsilon 4.000$ and 4.392$), \lambda_{\max }$. $(6 \mathrm{~N}-\mathrm{HCl}) 311$ and $215 \mathrm{~nm}(\log \varepsilon 4 \cdot 050$ and $4 \cdot 375), \delta\left(\mathrm{CDCl}_{3}\right)$ $7 \cdot 08$ and $6 \cdot 88(6-$ and $9-\mathrm{H}), 3 \cdot 53$ and 3.37 ( $1-$ and $3-\mathrm{Me}$ ), $2 \cdot 83(5-\mathrm{Me}$ ), $2 \cdot 25$ (7- and 8-Me), and 1.49 p.p.m. (4a-Me). 